\title{
KOMPRES DINGIN TITIK LI-4 KONTRA LATERAL TANGAN MENEKAN RESPON NYERI SELAMA INVASIF ARTERIOVENOUS FISTULA (AVF) PASIEN HEMODIALISA
}

\section{[COLD COMPRESS POINT LI-4 LATERAL CONS HAND EXPRESSING PAIN RESPONSE DURING INVASIVE ARTERIOVENOUS FISTULA (AVF) HEMODIALYSIS PATIENTS]}

\author{
Mahruri Saputra, Herlina A.N Nasution \\ STIKes Getsempena Lhoksukon Aceh \\ e-mail : mahruri68@gmail.com \\ DOI : 10.47718/jpd.v8i02.1175
}

\section{ABSTRAK}

Latar Belakang: Penusukan Arteriovenous fistula (AVF) akan menimbulkan nyeri berulang yang dapat mengganggu psikologis dan kenyamanan pasien yang menjalani hemodialisa. Salah satu terapi nonfarmakologi yang dapat digunakan untuk menurunkan nyeri yaitu kompres dingin pada titik LI-4. Tujuan: Penelitian ini bertujuan mengidentifikasi efektifitas kompres dingin titik LI-4 terhadap penurunan nyeri penusukan AVF pada pasien hemodialisa. Metode: Jenis penelitian ini yaitu kuantitatif dengan desain quasi experiment pre and post one sampel test. Pengambilan sampel dengan teknik consecutive sampling dengan jumlah 33 . Instrumen penelitian yang digunakan adalah Pain Numerical Rating Scale. Analisis data menggunakan Paired T-Test. Hasil: Sebelum dilakukan kompres dingin LI-4 rata-rata intensitas nyeri penusukan AVF 5,36 $(S D=1,47)$ dan sesudah pemberian kompres dingin titik LI4 rata-rata intensitas nyeri penusukan AVF $3,30(S D=0,95)$. Hasil uji didapatkan ada perbedaan intensitas nyeri penusukan AVF sebelum dan sesudah kompres dingin titik LI-4 pasien hemodialisa $(p=0,000)$. Kesimpulan: Terdapat perbedaan signifikan antara intensitas nyeri penusukan AVF sebelum dan sesudah pemberian kompres dingin titik LI-4. Saran: Diharapkan intervensi kompres dingin titik LI-4 dapat menjadi intervensi mandiri untuk mengurangi nyeri penusukan sehingga bisa meningkatkan kenyaman pasien hemodialisa.

Kata Kunci: Kompres dingin di titik LI-4, Nyeri dilokasi penusukan, Arteriovenous fistula. 


\section{ABSTRACT}

\section{PENDAHULUAN}

Introduction: Arteriovenous fistula (AVF) insertion will cause repeated pain that can disturb the psychology and comfort of the patient undergoing hemodialysis. One of the non-pharmacological therapies that can be used to reduce pain is a cold compress at point LI-4. Aim: This study aims to identify the effectiveness of cold compresses LI-4 point to reduce AVF stabbing pain in hemodialysis patients. Method: This type of research is quantitative with a quasi experimental design pre and post one sample test. Sampling with the consecutive sampling technique with a total of 33 . The instruments that were used in this research were Pain Numerical Rating Scale (PNRS). Data analysis using Paired T-Test. Results: Before doing the LI-4 cold compress the average intensity of AVF stabbing pain was $5.36(S D=1.47)$ and after giving cold compresses the LI-4 point the average intensity of AVF stabbing pain was 3.30 $(S D=0.95)$. The test results showed that there was a difference in the intensity of AVF stabbing pain before and after cold compresses, point LI-4 for hemodialysis patients $(p=0.000)$. Conclusion: There is a significant difference between the intensity of AVF stabbing pain before and after giving cold compress to the LI-4 point. Suggestion: It is hoped that the LI-4 point cold compress intervention can be an independent intervention to reduce stabbing pain so that it can increase the comfort of hemodialysis patients.

Key words: Cold compress at point LI-4, pain at the puncture site, arteriovenous fistula

$$
\text { Pada tahun } 2013 \text { di Amerika sebanyak } 468.000 \text { pasien }
$$

menjalani dialysis, dimana $88,2 \%$ diantaranya menjalani hemodialisa (National Institute of Diabetes and Digestive and Kidney Disease, 2016). Menurut laporan PENEFRI yang dimuat dalam Tenth Report of Indonesian Renal Registry tahun 2017 di Indonesia jumlah pasien baru yang menjalani hemodialisa sebanyak 30.831 orang dan pasien aktif sebanyak 77.892 orang. Sementara di propinsi Aceh pasien baru hemodialisa sebanyak 1342 orang 
(Perkumpulan Nefrologi Indonesia, 2017).

Pasien hemodialisa biasanya menggunakan dua jenis akses vaskuler eksternal yaitu Arteriovenous Fistula (AVF) dan Arteriovenous (AV) graft (Rosdahl \& Kowalski, 2012). Jenis akses vaskuler yang paling sering digunakan pasien hemodialisa yaitu AVF (Smeltzer, Bare, Hinkle, \& Cheever, 2010).

Menurut Sanusi (2015) periode satu tahun pasien hemodialisa akan mengalami luka tusukan sebanyak 200 kali apabila melakukan hemodialisa rutin dua kali seminggu. Nyeri tusukan AVF merupakan keluhan yang paling sering dirasakan pasien hemodialisa (Sabitha, et al, 2008). Menurut Figueiredo et al. nyeri saat insersi AVF merupakan penyebab tertinggi yang dikeluhkan pasien hemodialisa (Figueiredo, Viegas, Monteiro, \& Poli-de-Figueiredo, 2008).

Untuk mengurangi nyeri yang diakibatkan penusukan jarum AVF berulang maka perlu adanya usaha agar pasien dapat menjalani hemodialisa dengan baik dan nyaman (Celik, et al, 2011). Kompres dingin merupakan teknik non-farmakologi yang dapat digunakan perawat dalam menurunkan nyeri penusukan AVF (Aghajanloo, Ghafourifard, Haririan, \& Gheydari, 2016).

Kompres dingin dengan suhu $10-32^{\circ} \mathrm{C}$ selama 10 menit dapat mengurangi nyeri saat penusukan jarum pada pasien hemodialisa (Sanusi, 2015). Kompres dingin dapat dilakukan pada titik LI-4 kontralateral tangan. Titik LI-4 adalah lokasi pada tonjolan tertinggi ketika telunjuk dan ibu jari tangan dirapatkan 
(Kementerian Kesehatan Republik Indonesia, 2015).

Hasil penelitian Aghajanloo, Ghafourifard, Haririan dan Gheydari (2016) menunjukkan ada penurunan skala nyeri penusukan AVF yang signifikan antara sebelum perlakuan pada sesi pertama $(M=5.9 ; S D=0,96)$ dan setelah perlakuan pada sesi kedua $(M=3,2 ; S D=1,71)$. Menurut Golda et al, (2016) dari 60 responden yang diberikan kompres dingin titik LI-4 kontralateral tangan, menunjukkan sebanyak 3,33\% responden mengalami nyeri berat, $13,33 \%$ responden mengalami nyeri sedang, 36,67\% responden menglami nyeri ringan, dan $46,67 \%$ responden tidak menglami ada nyeri, dengan rata-rata nyeri $1,53(S D=0,77)$, jika dibandingkan dengan sebelum dilakukan perlakuan dimana sebanyak $43,33 \%$ responden mengalami nyeri berat dan $56,67 \%$ responden mengalami nyeri sedang, dengan rata-rata nyeri 6,3 $(S D=1,15)$. Keuntungan pemberian kompres dingin sangat mudah dilakukan, tidak membutuhkan biaya besar, dapat dilakukan oleh setiap pasien hemodialisa dan tidak mempunyai efek samping (Davtalab, Naji, \& Shahidi, 2016).

Berdasarkan studi pendahuluan yang dilakukan pada $30 \mathrm{Juli}$ di RSUD Aceh Tamiang didapatkan hasil bahwa seluruh pasien yang menjalani hemodialisa tidak diberikan terapi apapun untuk mengurangi nyeri saat dilakukan penusukan AVF. Berdasarkan latar belakang diatas maka penulis tertarik untuk melakukan penelitian tentang efektifitas kompres dingin titik LI-4 terhadap penurunan nyeri penusukan AVF pada pasien hemodialisa. 


\section{METODE PENELITIAN}

Penelitian ini merupakan jenis penelitian quantitative design dengan pendekatan desain quasi eksperimen pre and post one sampel test dalam bentuk time series. Populasi yang digunakan adalah seluruh pasien hemodialisa yang menggunakan akses vaskuler AVF di ruang hemodialisa RSUD Aceh Tamiang. Jumlah sampel penelitian ini diambil dari hasil penelitian sebelumnya yang dihitung berdasarkan tabel power analisis. Jumlah sampel yang didapatkan dari power 0,8 , effect size 0,7 , dan $\alpha=0,05$ adalah 33 responden. Metode dalam pengambilan sampel yang digunakan adalah consecutive sampling dimana pemilihan sampel dilakukan dengan memilih semua individu yang ditemui dan memenuhi kriteria sampai jumlah sampel yang dibutuhkan terpenuhi (Dharma, 2015).

Instrumen penelitian ini menggunakan Numerical Pain Rating Scale (NPRS) dan lembar pencatatan tingkat nyeri. Teknik pengumpulan data dilakukan dalam dua kali pertemuan pada pasien rutin melakukan hemodialisa dua kali seminggu. Pada pertemuan pertama, responden dinilai tingkat nyerinya saja setelah dilakukan penusukan AVF dan pada pertemuan kedua responden yang sama diberikan kompres dingin titik LI-4 kontralateral tangan selama 10 menit sebelum dan sampai penusukan dilakukan. Kemudian diukur tingkat nyeri responden.

Sampel penelitian yang diambil adalah responden yang menjalani hemodialisa rutin dan memenuhi kriteria inklusi yaitu Pasien menjalani hemodialisa rutin 2 kali seminggu yang datang ke 
ruang hemodialisa RSUD Aceh Tamiang, Tidak merasa sakit pada area tubuh yang lain sebelum penusukan jarum fistula, tidak memiliki riwayat menggunakan obat-obatan (narkoba), kanulasi AV fistula dapat dilakukan dari waktu ke waktu, tidak mengalami peradangan, kerusakan, kemerahan dan memar di kulit dimana jarum dimasukkan ke fistula, tidak mengalami sensitifitas terhadap es. Sedangkan kriteria eksklusi dalam penelitian ini adalah dengan alasan sepihak menghentikan keikutsertaan dalam penelitian, meninggal atau tidak melanjutkan perawatan pada pertemuan kedua, mengkonsumsi obat penenang sebelum memulai hemodialisa.

Analisis univariat dilakukan menggunakan analisis deskriptif melalui distribusi frekuensi dan persentase data yang meliputi umur, jenis kelamin, lama menjalani hemodialisa dan lama terpasang $\mathrm{AV}$ fistula, serta data intensitas nyeri pasien pada pertemuan pertama sebelum pemberian kompres dingin titik LI-4 (pretest) dan pertemuan kedua setelah pemebrian kompres dingin titik LI-4 (posttest). 
HASIL DAN PEMBAHASAN

\section{a. Karakterisitk Responden}

Tabel 1 Distrubusi frekuensi karakteristik responden di ruang Hemodialisa RSUD Aceh Tamiang $(n=33)$

\begin{tabular}{|c|c|c|}
\hline Karakteristik Responden & $f$ & $\%$ \\
\hline \multicolumn{3}{|l|}{ Usia (Tahun) } \\
\hline 17-25 (Remaja Akhir) & 4 & 12,1 \\
\hline 26-35 (Dewasa Awal) & 4 & 12,1 \\
\hline 36-45 (Dewasa Tengah) & 4 & 12,1 \\
\hline 46-55 (Dewasa Akhir) & 5 & 15,2 \\
\hline 56-65 (Lansia Awal) & 12 & 36,4 \\
\hline$>65$ (Lanjut Usia) & 4 & 12,1 \\
\hline Mean $\pm S D$ & \multicolumn{2}{|c|}{$48,64 \pm 15,44$} \\
\hline \multicolumn{3}{|l|}{ Jenis Kelamin } \\
\hline $\begin{array}{l}\text { Perempuan } \\
\text { Laki-laki }\end{array}$ & $\begin{array}{l}12 \\
21\end{array}$ & $\begin{array}{l}36,4 \\
63,6\end{array}$ \\
\hline \multicolumn{3}{|l|}{ Lama Menjalani HD (Bulan) } \\
\hline $3-28$ & 18 & 54,5 \\
\hline $29-54$ & 11 & 33,3 \\
\hline $55-78$ & 4 & 12,2 \\
\hline Mean $\pm S D$ & \multicolumn{2}{|c|}{$30,33 \pm 21,3$} \\
\hline \multicolumn{3}{|l|}{ Lama Terpasang AVF (Bulan) } \\
\hline $2-23$ & 19 & 57,6 \\
\hline $24-47$ & 10 & 30,3 \\
\hline $48-66$ & 4 & 12,1 \\
\hline Mean $\pm S D$ & \multicolumn{2}{|c|}{$23,03 \pm 18,2$} \\
\hline
\end{tabular}

Kelompok usia responden penelitian ini dikategorikan menurut Depkes RI (2009). Penelitian ini menemukan bahwa lebih dari sepertiga responden $(36,4 \%)$ berusia antara $56-65$ tahun atau dapat dikategorikan usia responden pada kelompok lansia awal dan kurang dari dua pertiga responden $(63,6 \%)$ berjenis kelamin lakilaki. Hasil penelitian ini juga menemukan, lebih dari sepertiga $(42,4 \%)$ responden. Sementara, berdasarkan lama menjalani HD, lebih dari setengah $(54,5 \%)$ responden telah menjalani HD selama 3-28 bulan dan lebih dari setengah $(57,6 \%)$ responden telah 
terpasang AVF 2-23 bulan dengan rata-rata lama terpasang AVF yaitu $23,03(S D=18,2)$.

Tabel 2 : Intensitas nyeri penusukan AVF sebelum dan sesudah kompres dingin titik LI-4 di ruang hemodialisa RSUD Aceh Tamiang $(n=33)$

\begin{tabular}{cccccc}
\hline & \multirow{2}{*}{ No } & Intensitas & \multicolumn{3}{c}{ Kompres Dingin Titik LI-4 } \\
\cline { 3 - 6 } & Nyeri & \multicolumn{2}{c}{ Sebelum } & \multicolumn{2}{c}{ Sesudah } \\
\cline { 3 - 6 } & & $f$ & 12,1 & 21 & 63,6 \\
\hline 1 & $1-3$ (Ringan) & 4 & 66,7 & 12 & 36,4 \\
2 & $4-6$ (Sedang) & 22 & 21,2 & 0 & 0 \\
3 & $7-10$ (Berat) & 7 & \multicolumn{2}{c}{$3,30 \pm 0,95$} \\
\hline
\end{tabular}

Pada pertemuan pertama sebelum dilakukan kompres dingin titik LI-4, sebanyak dua pertiga (66,7\%) responden mengalami nyeri penusukan AVF dengan intensitas 4-6 (sedang) dan rata-rata nyeri $5,36(S D=1,47)$. Sementara, pada pertemuan kedua sesudah pemberian kompres dingin titik LI-4, kurang dari dua pertiga $(63,6 \%)$ responden mengalami nyeri penusukan AVF dengan intensitas 1-3 (ringan) dan rata-rata nyeri 3,30 $(S D=0,95)$.

Uji normalitas data yang digunakan pada penelitian ini adalah skewness dan kurtosis. Kriteria distribusi data normal jika nilai rasio skewness dan kurtosis diantara rentang -2 s/d 2 (Dahlan, 2011). Pada pertemuan pertama sebelum dilakukan kompres dingin titik LI-4 didapatkan data berdistribusi normal dengan nilai rasio skewness/standart error skewness 0,62 dan nilai rasio kurtosis/standart error kurtosis -0,60. Pada pertemuan kedua setelah dilakukan kompres dingin titik LI-4 didapatkan data berdistribusi normal dengan nilai rasio skewness/standart error 
skewness 0,93 dan nilai rasio kurtosis/standart error kurtosis -0,94.

Analisis bivariat yang menggunakan uji beda 2 mean (pretest dan posttest) dengan analisa statistik dependent $t$-test (paired $t$ test) dilakukan untuk mengetahui perbedaan intensitas nyeri sebelum dan sesudah kompres dingin titik LI-4.

Tabel 3 Hasil analisis uji paired t-test perbedaan rata-rata intensitas nyeri penusukan AVF sebelum dan sesudah kompres dingin titik LI4 di ruang Hemodialisa RSUD Aceh Tamiang $(n=33)$

\begin{tabular}{lcccc}
\hline & $\begin{array}{c}\text { Selisih Nilai } \\
\text { Mean }\end{array}$ & $S D$ & $t$ & $p$ \\
\hline $\begin{array}{l}\text { Sebelum-Sesudah } \\
\text { Pemberian Kompres Dingin } \\
\text { Titik LI-4 }\end{array}$ & 2,061 & 1,368 & 8,653 & $\begin{array}{c}0,0 \\
00\end{array}$ \\
\hline
\end{tabular}

Perbedaan antara intensitas nyeri penusukan AVF sebelum dan sesudah kompres dingin titik LI-4 dengan rata-rata penurunan yaitu 2,061. Hasil uji analisis statistik juga menunjukkan bahwa intensitas nyeri penusukan AVF setelah dilakukan kompres dingin titik LI-4 diperoleh nilai $p=0,000$ dengan tingkat kepercayaan 95\%. Maka, dapat disimpulkan bahwa nilai $p<0,05$, yang artinya terdapat perbedaan intensitas nyeri penusukan AVF sebelum dan sesudah kompres dingin titik LI-4 pada pasien hemodialisa di RSUD Aceh Tamiang.

Berdasarkan nilai $t$, dimana nilai $t_{\text {tabel }}$ dengan nilai $d f=31$ adalah 2,039 $(\alpha=0,05)$. Maka, nilai $t_{\text {hitung }}$ pada tabel 4.4 dapat diinterpretasikan bahwa terdapat perbedaan signifikan antara sebelum dan sesudah kompres dingin titik LI-4 terhadap intensitas 
nyeri penusukan AVF pada pasien hemodialisa. Adapun nilai $t_{h i t u n g}$ dari kompres dingin yaitu 8,653.

Hasil penelitian ini menunjukkan bahwa, dari 33 responden sebelum diberikan kompres dingin titik LI-4 saat penusukan AVF pada pasien hemodialisa didapatkan bahwa sebanyak dua pertiga (66,7\%) responden mengalami nyeri penusukan AVF dengan intensitas 4-6 (sedang) dan rata-rata nyeri 5,36 (SD=1,47). Silva et al, (2016) dalam penelitiannya menyatakan dari 70 responden, lebih dari setengah $(58,5 \%)$ responden mengalami nyeri dengan intensitas sedang pada saat menjalani kanulasi AVF. Hasil penelitian ini didukung hasil oleh penelitian Kaza et al, (2014) dimana dari 56 responden yang mengalami nyeri penusukan AVF kurang dari duapertiga (62\%) responden mengalami intensitas nyeri sedang. Penelitian Celik et al, (2011) juga menemukan hasil yang sama bahwa dari 41 responden kurang dari setengah $(48,8 \%)$ responden pada kelompok tanpa intervensi mengalami nyeri sedang.

Penelitian Arab et al, (2017) juga menyatakan bahwa intensitas nyeri penusukan AVF sebelum intervensi yaitu sedang dengan nilai rata-rata $5.40(S D=1,75)$ dan $5,54(S D=1,22)$ pada kelompok lidocaine gel $2 \%$ dan hegu point ice massage. Penelitian Golda et al, (2016) juga menunjukkan hasil yang sama dimana intensitas nyeri penusukan AVF sebelum dilakukan intervensi dalam rentang yang sama yaitu sedang dengan nilai rata-rata 6,3 $(S D=1,15)$.

Intensitas nyeri penusukan AVF dapat berkaitan dengan faktor usia, dimana lebih dari sepertiga responden (36,4\%) berusia 
antara 56-65 (lansia awal) dengan rata-rata usia responden 48,64 tahun. Hasil penelitian yang dilakukan Sanusi (2015) menyebutkan bahwa distribusi responden yang mengalami nyeri sedang yang berusia kurang dari 65 tahun yaitu sebanyak 87\%. Helms dan Barone (2008) menyatakan bahwa pada usia lanjut, serabut C lebih sering bekerja dibandingkan dengan serabut A-delta. Selain itu, kemampuan komunikasi, kognitif dan kerusakan reflex juga dapat menjadi penyebab perlambatan peyampaian rasa nyeri pada lansia.

Selanjutnya, intensitas nyeri penusukan AVF tidak terkait dengan jenis kelamin. Dimana, hasil penelitian ini menunjukkan bahwa kurang dari dua pertiga responden $(63,6 \%)$ berjenis kelamin laki-laki. Hasil penelitian yang dilakukan oleh Aitken et al, (2013) menunjukkan tidak ada hubungan yang signifikan antara nyeri penusukan AVF dengan jenis kelamin. Sedangkan hasil penelitian yang dilakukan Sabitha et al, (2008) mendapatkan hasil bahwa intensitas nyeri penusukan AVF lebih dirasakan pada wanita. Menurut Palmeira, Ashmawi dan Posso (2011) wanita cenderung memiliki ambang nyeri yang lebih rendah dibandingkan dengan pria, karena rasa sakit dipengaruhi oleh mekanisme yang dapat merangsang atau menghambat sensasi nyeri. Mekanisme potensial yang dapat mempengaruhi nyeri yaitu hormon, perbedaan otak dan sumsum tulang belakang antara pria dan wanita, genetik, peran sosial budaya, stres, dan agen-agen neuroaktif (Helms \& Barone, 2008).

Berdasarkan hasil uraian diatas, rata-rata intensitas nyeri penusukan AVF sebelum dilakukan intervensi yang dialami pasien 
hemodialisa dalam kategori sedang. Sementara, karakteristik umur pasien dapat mempengaruhi intensitas nyeri penusukan AVF yang dirasakan oleh pasien. Sedangkan jenis kelamin tidak berkaitan secara langsung terhadap intensitas nyeri penusukan AVF yang dirasakan pasien hemodialisa.

Berdasarkan hasil penelitian, dari 33 pasien yang dilakukan tindakan kompres dingin titik LI-4 saat penusukan AVF didapatkan hasil bahwa kurang dari dua pertiga $(63,6 \%)$ responden mengalami penurunan nyeri penusukan AVF dengan intensitas 1-3 (ringan) dan rata-rata nyeri $3,30(S D=0,95)$. Hasil penelitian yang dilakukan Davtalab, Naji, dan Shahidi (2016) menyatakan bahwa dari 35 responden yang dilakukan kompres dingin kontralateral hand kurang dari dua pertiga (60\%) responden menglami nyeri sedang. Namun, jumlah ini menurun dibandingkan dengan sebelum pemberian kompres dingin kontralateral hand yaitu nyeri dirasakan sebanyak 74,3\% responden. Hal ini karena sebanyak 13,4\% responden mengalami penurunan intensitas nyeri menjadi nyeri ringan.

Kompres dingin LI-4 merupakan salah satu intervensi yang dapat menurunkan nyeri penusukan AVF. Menurut Fareed, El-Hay dan El-shikh (2014) kompres dingin merupakan teknik stimulasi kutaneus yang dapat menurunkan nyeri. Mekanisme kompres dingin dalam menurunkan nyeri dapat dijelaskan berdasarkan teori yang dikembangkan Melzak dan Wall tahun 1965 tentang gate control. Rangsangan dari kompres dingin dapat mengaktivasi serabut saraf sensori A-beta yang berdiameter besar. Peningkatan 
rangsangan serabut A-beta dapat menjadi kompetitor dan menghalangi konduksi serabut tipis A-delta dan serabut C (serabut nyeri) dengan cara menutup gerbang pada area dorsal horn sumsum tulang belakang sehingga mengurangi transmisi nyeri yang dihantarkan serabut A-delta dan serabut C.

Kompres dingin kontralateral hand dilakukan pada titik LI-4 atau hegu point. Kompres dingin pada titik ini efektif dalam menurunkan nyeri (Golda et al, 2016). Titik LI-4 terletak kira-kira ditengah tulang metakarpal kedua antara tulang metakarpal satu dan dua (Jing, 1990). Rangsangan terhadap titik LI-4 dapat melepaskan zat peptida opiod endogen yang dapat mengurangi rasa nyeri (Saputra, 2002).

Hasil uji statistik terhadap nyeri penusukan AVF didapatkan bahwa, intensitas nyeri penusukan AVF setelah kompres dingin kontralateral hand yaitu ringan dengan nilai rata-rata 3,24 $(S D=1,04)$ (tabel 4.2). Hasil penelitian yang dilakukan Sabitha et al, (2008) juga menyatakan nyeri penusukan AVF pada kelompok krioterapi pada intensitas ringan dengan nilai median 2 (min$\max =1-2,5)$.

Penurunan intensitas nyeri penusukan AVF dapat dikaitkan dengan faktor usia. Penurunan sensori terjadi pada pasien yang berusia lanjut. Hasil penelitian ini menunjukkan lebih dari sepertiga responden $(39,7 \%)$ berusia antara 56-65 (lansia awal) dengan ratarata usia responden 49,38 tahun. Hasil penelitian yang dilakukan Sanusi (2015) menyebutkan bahwa distribusi responden yang mengalami nyeri sedang yang berusia kurang dari 65 tahun yaitu 
sebanyak 87\%. Helms dan Barone (2008) menyatakan bahwa pada usia lanjut, serabut $\mathrm{C}$ lebih sering bekerja dibandingkan dengan serabut A-delta. Selain itu, kemampuan komunikasi, kognitif dan kerusakan reflex juga dapat menjadi penyebab perlambatan peyampaian rasa nyeri pada lansia. Karena rata-rata usia pada hasil penelitian ini masih pada kategori lansia awal maka pemberian teknik kompres dingin kontralateral hand efektif dalam menurunkan nyeri. Hal ini disebabkan karena stimulasi sensori pada kutaneus yang diberikan masih dapat di respon dengan baik oleh system saraf pasien.

Sementara, intensitas nyeri penusukan AVF tidak terkait dengan jenis kelamin. Hasil penelitian ini menunjukkan bahwa kurang dari dua pertiga responden $(63,5 \%)$ berjenis kelamin lakilaki. Hasil penelitian yang dilakukan oleh Aitken et al, (2013) menunjukkan tidak ada hubungan yang signifikan antara nyeri penusukan AVF dengan jenis kelamin. Sedangkan hasil penelitian yang dilakukan Sabitha et al, (2008) mendapatkan hasil bahwa intensitas nyeri penusukan AVF lebih dirasakan pada wanita. Menurut Palmeira, Ashmawi dan Posso (2011) wanita cenderung memiliki ambang nyeri yang lebih rendah dibandingkan dengan pria, karena rasa sakit dipengaruhi oleh mekanisme yang dapat merangsang atau menghambat sensasi nyeri. Mekanisme potensial yang dapat mempengaruhi nyeri yaitu hormone, perbedaan otak dan sumsum tulang belakang antara pria dan wanita, genetik, peran sosial budaya, stres, dan agen-agen neuroaktif (Helms \& Barone, 2008). 
Berdasarkan uraian diatas, setelah dilakukan kompres dingin

titik LI-4 terjadi penurunan intensitas nyeri penusukan AVF pada pasien hemodialisa. Hal ini dapat dikaitkan dengan rata-rata usia pasien dalam kategori lansia awal sehingga stimulasi dingin yang diberikan masih dapat direspon dengan baik oleh pasien. Sementara itu, jenis kelamin tidak mempengaruhi intensitas nyeri penusukan karena kurang dari dua pertiga pasien berjenis kelamin laki-laki.

Terdapat penurunan nyeri penusukan AVF setelah pemberian kompres dingin titik LI-4 dengan rata-rata penurunan intensitas nyeri yaitu 2,061. Dimana, nyeri penusukan AVF yang dialami responden tanpa diberikan intervensi berada pada intensitas nyeri sedang dengan nilai rata-rata 5,36 menjadi nyeri ringan dengan nilai rata-rata 3,30 setelah pemberian kompres dingin titik LI-4.

Berdasarkan hasil uji statistik didapatkan nilai $t_{\text {hitung }}=8,653$ dan nilai $p=0,000$. Artinya, terdapat perbedaan signifikan antara intensitas nyeri penusukan AVF tanpa intervensi dengan pemberian kompres dingin titik LI-4. Dimana, dengan pemberian kompres dingin titik LI-4 dapat menurunkan nyeri penusukan AVF pada pasien hemodialisa.

Hasil penelitian ini didukung oleh penelitian yang dilakukan oleh Saputra, Harahap dan Kasiman (2018) yang menunjukkan bahwa ada perbedaan antara sebelum diberikan intervensi (pretest) dengan pemberian kompres dingin kontralateral hand (posttest) $(t=15,30, p=0.000)$. Davtalab, Naji dan Shahidi (2016) juga 
menyatakan ada perbedaan antara intensitas nyeri penusukan sebelum dan sesudah pemberian pijat es pada titik hoku $(p=0,003)$.

Penelitian yang dilakukan Sanusi (2015) juga menunjukkan ada perbedaan yang intensitas nyeri yang dialami oleh responden sebelum pemberian intervensi dan sesudah pemberian intervensi kompres dingin $(p<0,001)$. Penelitian yang dilakukan oleh Soltanpuor, Mohamadi dan Haghani (2012) juga mendukung hasil penelitian ini yang menunjukkan terdapat perbedaan yang signifikan intensitas nyeri pada kelompok AVF setelah dilakukan intervensi pijat es pada titik hoku $(p=0,001)$.

Kompres dingin kontralateral hand pada titik LI-4 atau hegu point efektif dalam menurunkan intensitas nyeri (Golda et al, 2016). Mekanisme kompres dingin dalam menurunkan nyeri dapat dijelaskan berdasarkan teori yang dikembangkan Melzak dan Wall tahun 1965 tentang gate control. Stimulasi dari kompres dingin dapat mengaktivasi serabut saraf sensori A-beta yang berdiameter besar. Peningkatan rangsangan serabut A-beta dapat menjadi kompetitor dan menghalangi konduksi serabut tipis A-delta dan serabut C (serabut nyeri) dengan cara menutup gerbang pada area dorsal horn sumsum tulang belakang sehingga mengurangi transmisi nyeri yang dihantarkan serabut A-delta dan serabut C.

Menurut Wu et al, (1999) dan Lee, LaRiccia dan Newberg (2004) bahwa rangsangan yang diberikan pada titik LI-4 yang dihantarkan melalui sumsum tulang belakang, dapat mengakativasi hipotalamus dan kelenjar pituitari untuk melepaskan zat peptida opiod endogen ke area periaqueductal gray matter (PAG) dan 


\section{KESIMPULAN}

\section{DAFTAR PUSTAKA}

nucleus raphe magnus (NRM). Kemudian, zat peptida opiod endogen menghambat nyeri dengan mekanisme opiod yang mengakibatkan terjadinya efek analgesik sehingga menghambat semua impuls nyeri pada dorsal horn sumsum tulang belakang.

Menurut asumsi peneliti penurunan nyeri disebabkan karena rangsangan pada titik LI-4 dapat mengakativasi hipotalamus dan kelenjar pituitari untuk melepaskan zat peptida opiod endogen dan zat tersebut dapat menghambat jalur nyeri.

Pemberian kompres dingin di titik LI 4 kontra lateral tangan sangat efektif menekan respons nyeri yang berdampak pada kecemasan akibat dari penusukan AVF yang berulang.

Aghajanloo, A., Ghafourifard, M., Haririan, H., \& Gheydari, P. S. (2016). Comparison of the effects of cryotherapy and placebo on reducing the pain of arteriovenous fistula cannulation among hemodialysis patients: A randomized control trial. Journal of Nursing and Midwifery Sciences, 3(1): 59-65.

Aitken, E., McLellan, A., Glen, J., Serpell, M., Mactier, R., \& Clancy, M. (2013). Pain resulting from arteriovenous fistulae: prevalence and impact. Clinical Nephrology, 80(5): 328 333. DOI: $10.5414 / C N 107917$.

Arab, V., Nesami, M. B., Mousavinasab, S. N., Espahbodi, F., \& Zahra Pouresmail, Z. (2017). Comparison of the effects of hegu point ice massage and $2 \%$ lidocaine gel on arteriovenous fistula puncture-related pain in hemodialysis patients: $A$ randomized controlled trial. Journal of Caring Sciences, 6(2): 141-151. DOI:10.15171/jcs.2017.014.

Celik, G., Ozbek, O., Yilmaz, M., Duman, I., Ozbek, S., \& Apiliogullari, S. (2011). Vapocoolant spray vs lidocaine/prilocaine cream for reducing the pain of venipuncture in hemodialysis 
patients: a randomized, placebo-controlled, crossover study. International Journal of Medical Sciences, 8, 623-627.

Dahlan, M. S. (2011). Statistik untuk kedokteran dan kesehatan (edisi 5). Jakarta: Salemba Medika.

Davtalab, E., Naji, S., \& Shahidi, S. (2016). Comparing the effects of Valsalva maneuver and ice massage at Hoku point methods on pain intensity within the needle insertion to the arteriovenous fistula (AVF) for patients undergoing hemodialysis in the selected hospitals in Isfahan in 2015. International Journal of Medical Research \& Health Sciences, 5(5): 101-107.

Dharma, K. K. (2015). Metodelogi penelitian keperawatan: Panduan melaksanakan dan menerapkan hasil penelitian. Jakarta: Trans Info Media.

Figueiredo, A. E., Viegas, A., Monteiro, M., \& Poli-de-Figueiredo C. E. (2008). Research into pain perception with arteriovenous fistula (AVF) cannulation. Journal of Renal Care, 34, 169-172.

Fareed, M. E., El-hay, A. H. A., \& El-Shikh, A. A. (2014). Cutaneous stimulation: its effect on pain relieving among hemodialysis patients. Journal of Education and Practice, 5(1): 9-20. ISSN 2222-1735 (Paper), ISSN 2222-288X (Online).

Golda, M., Revathi, D., Subhashini, N., Mathew, J., \& Indira, A. (2016). Assess the effectiveness of cold application on pre procedure (AV fistula puncture) pain among hemodialysis patients in tertiary care hospital, Nellore. International Journal of Applied Research, 2(6): 660-664.

Helms, J. E., \& Barone, C. P. (2008). Physiology and treatment of pain. Critical Care Nurse, 28(6): 38-50.

Jing, C. (1990). Anatomical atlas of chinese acupuncture points. China: Shandong Science and Technology Press. 
Kaza, B. N. K., Sabi, K. A., Amekoudi, E.Y. M., Imangue, G., Badibanga, J., Tsevi, C. M., ...Ramdani, B. (2014). Pain during arterio-venous fistula (AVF) cannulation. American Journal of Internal Medicine, 2: 87-89.

Kementerian Kesehatan Republik Indonesia. (2015). Panduan akupresur mandiri bagi pekerja di tempat kerja. Direktorat Jenderal Bina Gizi dan Kesehatan Ibu dan Anak: Jakarta.

Lee, B, Y., LaRiccia, P. J., \& Newberg, A. B. (2004). Acupuncture in Theory and Practice Part 1: Theoretical Basis and Physiologic Effects. Hospital Physician, 11-18. www.turner-white.com.

Melzack, R., \& Wall, P. D. (1965). Pain Mechanisms: A New Theory. Science New Series, 50(699): 971-979.

National Institute of Diabetes and Digestive and Kidney Disease [NIDDK]. (2016). Kidney Disease Statistics for the United States. Diakses dari https://www.niddk.nih.gov/healthinformation/health-statistics/kidney-disease pada tanggal 05 April 2020.

Palmeira, C. C. A., Ashmawi, H. A., \& Posso, I. P. (2011). Sex and Pain Perception and Analgesia. Revista Brasileira de Anestesiologia, 61, 814-828. DOI: 10.1016/S00347094(11)70091-5.

Perkumpulan Nefrologi Indonesia [PENEFRI]. (2017). Tenth Report of Indonesian Renal Registry. Diakses dari https://www.indonesianrenalregistry.org/data/IRR\%202017 \%20.pdf pada tanggal 05 April 2020.

Rosdahl, C. B., \& Kowalski, M. T. (2012). Textbook of basic nursing. Philadelphia: Lippincott Williams \& Wilkins.

Sabitha, P. B., Khakha, D. C., Mahajan, S., Gupta, S., Agarwal, M., \&Yadav, S. L. (2008). Effect of cryotherapy on arteriovenous fistula puncture-related pain in hemodialysis patients. 
Indian Journal of Nephrology, 18: 155-158.

Sanusi, S. (2015). Perbandingan Efek Kompres Hangat Dengan Kompres Dingin Terhadap Intensitas Nyeri Saat Insersi Jarum Pada Pasien Gagal Ginjal Yang Menjalani Hemodialisis Rutin Di Rumah Sakit Muhammadiyah Bandung. Jurnal Keperawatan 'Aisyiyah (JKA), 2: 69-79.

Saputra, M., Harahap, I.K., \& Kasiman, S. (2018). Pengaruh Pemberian Teknik Valsava Manuver, Kompres Dingin Kontralateral Hand, dan Kombinasi Keduanya Terhadap Intensitas Nyeri Penusukan Arteriovenous (AV) Fistula pada Pasien Hemodialisa di Medan. Tesis. Fakultas Keperawatan Universitas Sumatera Utara.

Saputra, K. (2002). Akupunktur klinik. Surabaya: Airlangga University Press.

Silva, G. dos. S. T., Silva, R. A. da., Nicolino, A. M., Pavanetti, L. C., Alasmar, V. L., Guzzardi, R., ...\& Araujo, I. de. M., (2010). Initial experience with the buttonhole technique in a Brazilian hemodialysis center. J Bras Nefrol, 32(3): 256-260.

Smeltzer, S. C., Bare, B. G., Hinkle, J. L., \& Cheever K. H. (2010). Brunner \& Suddarth's Textbook of Medical-Surgical Nursing. Twelftth Edition. Philadelphia: Lippincott Williams \& Wilkins.

Soltanpour, F. N., Mohamadi, N., \& Haghani, H. (2012). Effect of huko point ice massage on pain degree during arterio venous fistula puncture in hemodialysis patients. Tehran: Tehran University of Medical Sciences.

Wu, M-T., Hsieh, J-C., Xiong, J., Yang, C-F., Pan, H-B., Chen, Y-C., I., ...Kwong, K. K. (1999). Central nervous pathway for acupuncture stimulation: localization of processing with functional MR Imaging of the brain-preliminary experience. Radiology, 202(1): 133-141. 